\title{
DÜBLIN
}

Technological University Dublin ARROW@TU Dublin

2007-01-01

\section{Design of Compact Multi-band EBG Structures}

\author{
Xiulong Bao \\ Technological University Dublin, xiulong.bao@tudublin.ie \\ Max Ammann \\ Technological University Dublin, max.ammann@tudublin.ie
}

Follow this and additional works at: https://arrow.tudublin.ie/engschececon

Part of the Electrical and Computer Engineering Commons

\section{Recommended Citation}

Bao, X. \& Ammann, M. (2007) Design of compact multi-band EBG structures. EuCAP 2007: Second European Conference on Antennas and Propagation, Edinburgh, Scotland, 11-16 November, 2007, doi:10.21427/D7PK6J

This Conference Paper is brought to you for free and open access by the School of Electrical and Electronic Engineering at ARROW@TU Dublin. It has been accepted for inclusion in Conference papers by an authorized administrator of ARROW@TU Dublin. For more information, please contact arrow.admin@tudublin.ie, aisling.coyne@tudublin.ie,gerard.connolly@tudublin.ie.

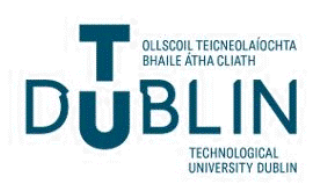




\title{
Design of Compact Multi-band EBG Structures
}

\author{
X.L. Bao and M. J. Ammann \\ Centre for Telecommunications Value-chain Research, \\ School of Electronic \& Communications Engineering, \\ Dublin Institute of Technology, Kevin Street, Dublin 8, Ireland
}

\begin{abstract}
Keywords: High-impedance EBG structure, of EBG structures. In [4-6], the convoluted metal strips Transmission characteristics, Multi-band of EBG cells are employed to increase the inductance and reduce the resonant frequency. But its stopband width is very narrow and the only the characteristics of a single stopband are investigated. Therefore it is limited in application.

In this paper, we study several compact EBG structures, which can provide the characeristics of multiple bandgap and realize miniaturization. By adjusting the distance between the strips according to log periodic distances, the various ratios of centre frequencies for multiple bandstop can be achieved.
\end{abstract}

\begin{abstract}
Several novel compact multiple-band high-impedance surface $\mathrm{EBG}$ structures are presented. By utilizing four S-shape corrugated arms or spiral arms connected to the edge of a small square patch to increase the inductance, the resonant frequency of the $\mathrm{EBG}$ structure can be significantly reduced. In order to broaden the width of the stopband and adjust the ratio of the centre frequencies for multi-band EBG, a log periodic distance between the S-shape strips is implemented. The effects of the parameters of the EBG structure on the width of stopbands are discussed in detail. The results show that the proposed novel EBG structure can provide more multiple bandgap and reduce the EBG size for a fixed periodicity. This proposed EBG can be usefully applied to multiple frequency antennas and low frequency antennas.
\end{abstract}

\section{Introduction}

In recent decades, there has been increased interest in investigating electromagnetic bandgap structures (EBG), and various EBG structures as applied to microwave circuits and antennas have been reported. Generally, the periodic length of EBG structure is about a half-wavelengh with respect to the centre-frequency and the bandstop is narrow. So the investigations on the compact, broadband and multiband EBG structure have also been attractive to many researchers. In [1-3], the high-impedance surface structure, which is composed of square metal and metal pads via the ground plane, is introduced and analyzed in detail. Then, some new techniques, which are mostly to increase the inductance or capacitance, are utilized to improve the characteristics

\section{Design of Several Compact High-Impedance EBG Structures}

A high-impedance surface (HIS) EBG cell can be considered as an LC network model, its first resonant frequency $f_{0}=\frac{1}{2 \pi \sqrt{L \cdot C}}$, and the relative bandstop width of EBG structure is $\frac{1}{\eta} \sqrt{\frac{L}{C}}$. For a HIS cell with square-shaped metal, the values of inductance $L$ and capacitance $C$ are approximated by the formula [7]:

$$
\begin{gathered}
C=\frac{\varepsilon_{0}\left(1+\varepsilon_{r}\right) P w}{\pi} \cosh ^{-1}\left(\frac{P a}{g}\right), \\
L=\mu_{0} \cdot h \cdot(\ln (1 / \alpha)+\alpha-1)
\end{gathered}
$$

Where $\alpha$ is the ratio of the via's metal pole cross sectional area to the unit cell area of $\mathrm{EBG}, h$ is the thickness of substrate. Pa: periodical length, $P a=g+$ $P w, g$ is the gap distance between the square metals, $P w$ : the length of square metal.

To reduce the resonant frequency and reduce the size of EBG structure, several different metal shape arms are connected to a small square metal via ground plane, as shown in Figure1. 


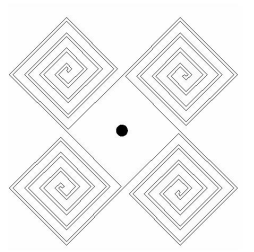

(a)

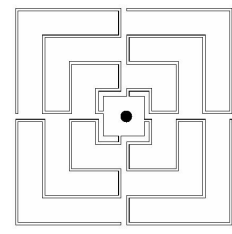

(b)

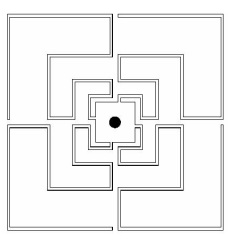

(c) (a) with four spiral arms (b) with four equal-distance S-shaped arms (c) with four log-periodic- spaced S-shaped arms

Figure 1 The geometries of three compact EBG cells

In order to adjust the ratio of multiband centre frequency and increase the width of the stopband of the electromagnetic bandgap structure, log periodic structures are employed in the proposed EBG structure. The log periodic structure is shown in Figure 2.

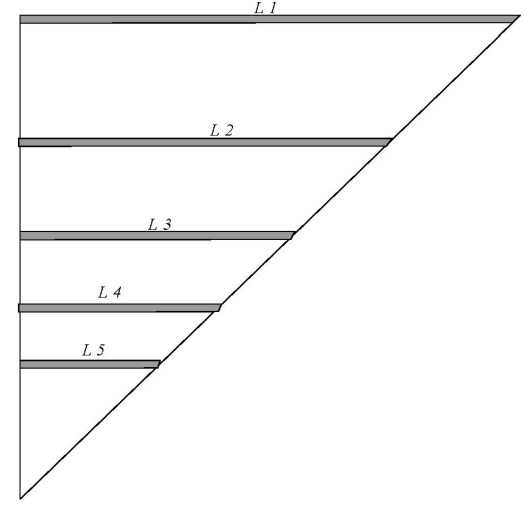

Figure 2 The $\log$ periodic structure

Ratio $\mathrm{p}=\frac{L 1}{L 2}=\frac{L 2}{L 3}=\frac{L 3}{L 4}=\frac{L 4}{L 5}=\cdots=\frac{L_{n}}{L_{n-1}}$

\section{Analysis on Transmission Coefficients of Compact Multi-Band High-Impedance EBG Structure}

The proposed compact EBG structures are fabricated using the substrate FR4, which has a relative permittivity of 4.2 , a thickness of $1.52 \mathrm{~mm}$, tan loss of 0.02. Several metal patches are connected to the ground plane via a metal pole of radius $0.5 \mathrm{~mm}$. The top layer on the high impedance surface structure has a $6.0 \mathrm{~mm}$ width microstrip line which is in accordance with $50 \mathrm{Ohm}$ input impedance. The simulation models of the transmission coefficients for the high-impedance surface EBG structure is shown in Figure 3.

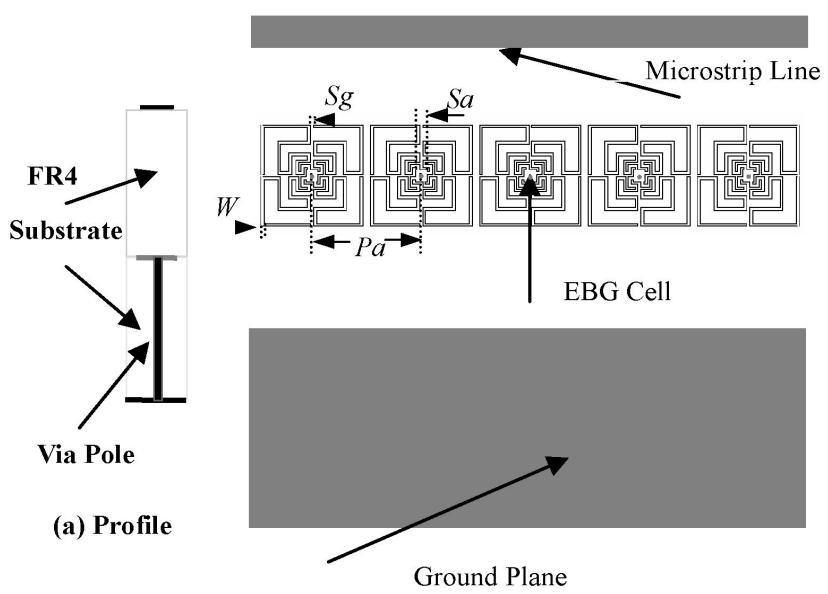

(b) The configuration of HIS EBG

Figure 3 The model of transmission line for HIS EBG

For S-shape or spiral armed corrugated EBG structure, its first resonant stopband will be reduced because of increasing the inductance. At the same time, the centre-frequencies of the multiple stopbands can be tuned by changing the ratio of the log period. In comparison to the conventional square metal EBG structure, the proposed EBG structure can provide wideband and multiple stopband characteristcs. The effects of various parameters for the proposed EBG structure are simulated and studied below:

\subsection{Effect of patch shapes}

Using the four-armed S-shape or spiral patch embedded into the small square metal connecting to the ground plane through metal pads to increase the inductance, the first resonant frequency will be significantly reduced, as listed in Figure 4 and Table 1. For the S-shaped metal EBG structure with log periodic distance between the strips, the widths of the bandstop can be broadened.

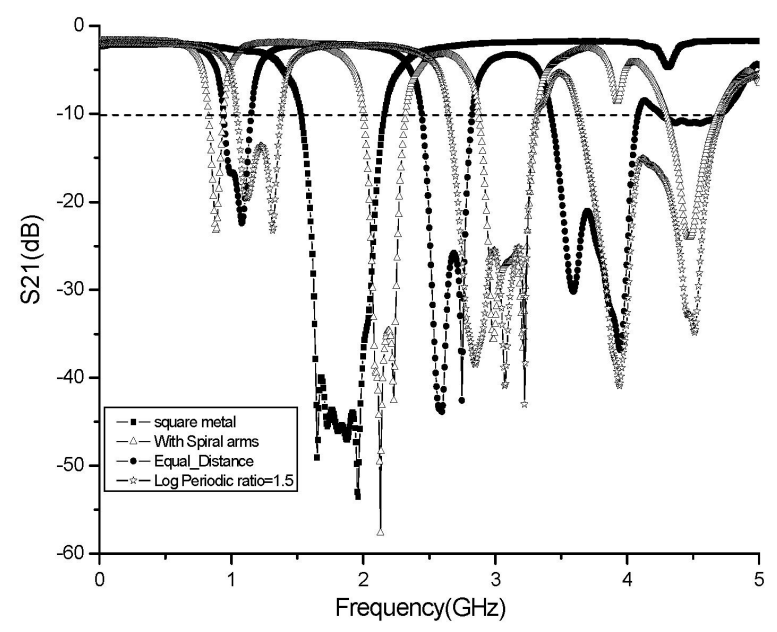

Figure 4 Comparison of S21 for different metal shapes EBG 
Table1. Comparison of multi-band and stopband width for different metal shapes

(periodic length $P a=18 \mathrm{~mm}, P w=16.0 \mathrm{~mm}, S g=0.4 \mathrm{~mm}, S a=2.0 \mathrm{~mm}$, $g=2.0 \mathrm{~mm}$, metal pole radius $=0.5 \mathrm{~mm}$, width of $\operatorname{strip} w=0.2 \mathrm{~mm}$ )

\begin{tabular}{|c|l|l|l|}
\hline \multicolumn{1}{|c|}{ Types } & $\begin{array}{l}\text { f1(GHz) } \\
\text { BW (\%) }\end{array}$ & $\begin{array}{l}\text { f2(GHz) } \\
\text { BW(\%) }\end{array}$ & $\begin{array}{l}\text { f3(GHz) } \\
\text { BW(\%) }\end{array}$ \\
\hline Square metal & 1.846 & ----- & ----- \\
\hline Spiral metal & $34.6 \%$ & & \\
\hline Equal Distance & 1.048 & 2.161 & 3.092 \\
& $12.0 \%$ & $14.2 \%$ & $14.2 \%$ \\
\hline Log distance & 1.210 & 2.629 & 3.769 \\
(p=1.5) & $27.5 \%$ & $14.3 \%$ & $18.4 \%$ \\
\hline
\end{tabular}

\subsection{Effect of ratio of $\log$ period between the strips}

In comparison with the conventional square metal HIS, the four-armed S-shaped metal EBG with the variousdiffer differrent distances between the metal strips can significantly increase the inductance and reduce the resonant frequency. If the distances between the metal strips are adjusted, the inductances and capacitances for HIS EBG cell are changed. So the ratio of multiband centre frequency is changed and the broad width of the stopband can also be obtained. The simulated results are displayed in Figure 5 and are listed in Table 2. It is noted that the ratio of the triband centre frequency can be tuned from $1: 2.4: 3.4$ to $1: 2.6: 3.6$ because of the change of inductances and capacitances in EBG cell while the ratios of log periodic length changed from 1.3 to 1.5 .

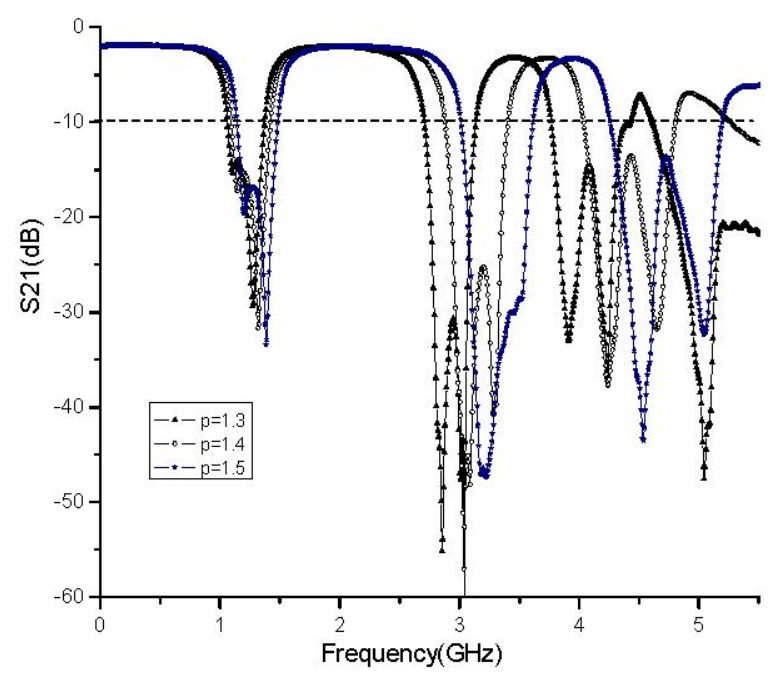

Figure 5 Comparison of S21 for different Log-periodic EBG
Table2. Comparison of multi-band and stopband width for different ratio of $\log$ period between the strips

(periodic length $P a=15 \mathrm{~mm}, P w=13.6 \mathrm{~mm}, S g=0.4 \mathrm{~mm}, S a=2.0 \mathrm{~mm}$, $g=1.4 \mathrm{~mm}$, metal pole radius $=0.5 \mathrm{~mm}$, width of $\operatorname{strip} w=0.2 \mathrm{~mm}$ )

\begin{tabular}{|c|l|l|l|l|}
\hline $\begin{array}{c}\text { Ratio of } \\
\text { log period }\end{array}$ & $\begin{array}{l}\text { f1(GHz) } \\
\text { BW(\%) }\end{array}$ & $\begin{array}{l}\text { F2(Ghz) } \\
\text { BW(\%) }\end{array}$ & $\begin{array}{l}\text { f3(GHz) } \\
\text { BW(\%) }\end{array}$ & f1/f2/f3 \\
\hline 1.3 & 1.206 & 2.912 & 4.095 & $1: 2.4: 3.4$ \\
& $27.3 \%$ & $15.2 \%$ & $16.5 \%$ & \\
\hline 1.4 & 1.264 & 3.146 & 4.416 & $1: 2.5: 3.5$ \\
& $26.8 \%$ & $16.8 \%$ & $17.6 \%$ & \\
\hline 1.5 & 1.295 & 3.315 & 4.734 & $1: 2.6: 3.6$ \\
& $26.5 \%$ & $18.9 \%$ & $20.0 \%$ & \\
\hline
\end{tabular}

\subsection{Effect of width of strips}

While the widths of strips for S-shape HIS EBG structure with $\log$ periodic ratio $\mathrm{p}=1.5$ are changed from $0.2 \mathrm{~mm}$ to $0.8 \mathrm{~mm}$, the centre frequencies of multiple stopband will be somewhat raised and the widths of stopband will also become wider in comparison to other HIS EBG structures. The simulation results are shown in Figure 6 and are listed in Table 3 in detail. It is found that the widths of first, second and third stopband, for the EBG structure with $0.8 \mathrm{~mm}$ width of strips are $38 \%$, $24 \%$, and $25 \%$, respectively.

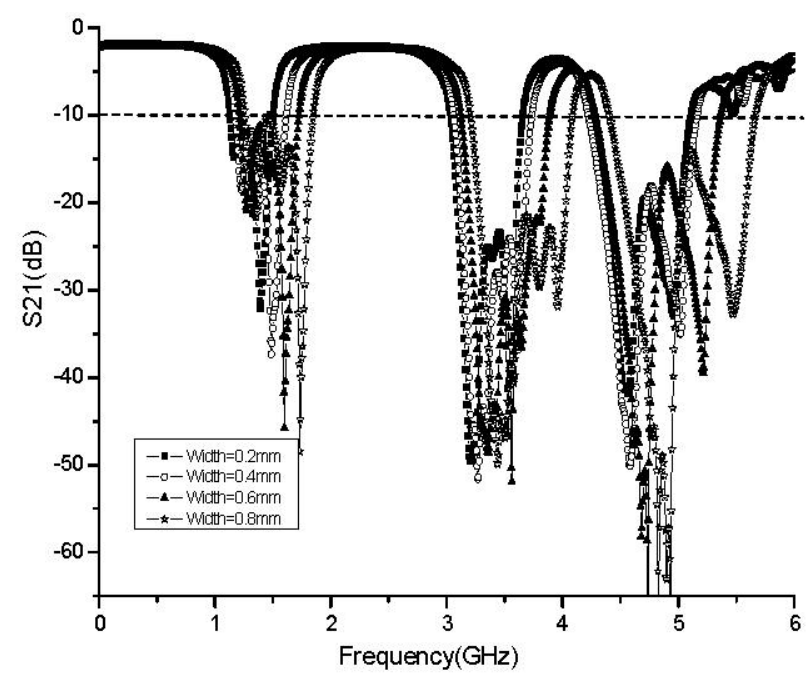

Figure 6 Comparison of S21 for HIS EBG structure for different strip widths 
Table3. Comparison of multi-band and stopband width for different strip widths

( periodic length $P a=15 \mathrm{~mm}, P w=13.6 \mathrm{~mm}, p=1.5$,

$S a=2.0 \mathrm{~mm}, S g=0.4 \mathrm{~mm}, g=1.4 \mathrm{~mm}$, metal pole radius $=0.5 \mathrm{~mm}$ )

\begin{tabular}{|c|c|c|c|}
\hline Width of strips & $\begin{array}{c}\text { f1(GHz) } \\
\text { BW(\%) }\end{array}$ & $\begin{array}{c}\text { F2(Ghz) } \\
\text { BW(\%) }\end{array}$ & $\begin{array}{c}\text { f3(GHz) } \\
\text { BW(\%) }\end{array}$ \\
\hline $0.2 \mathrm{~mm}$ & 1.323 & 3.335 & 4.666 \\
& $28.7 \%$ & $19.0 \%$ & $18.2 \%$ \\
\hline $0.4 \mathrm{~mm}$ & 1.396 & 3.397 & 4.687 \\
& $31.8 \%$ & $19.6 \%$ & $20.1 \%$ \\
\hline $0.6 \mathrm{~mm}$ & 1.466 & 3.507 & 4.817 \\
& $34.7 \%$ & $22.2 \%$ & $22.1 \%$ \\
\hline $0.8 \mathrm{~mm}$ & 1.557 & 3.640 & 5.028 \\
& $38.0 \%$ & $24.0 \%$ & $25.2 \%$ \\
\hline
\end{tabular}

\subsection{Effect of via metal pole radius size}

For different sizes of metal pole radius, small changes in inductance will cause a small change in the resonant frequency of HIS EBG structure.

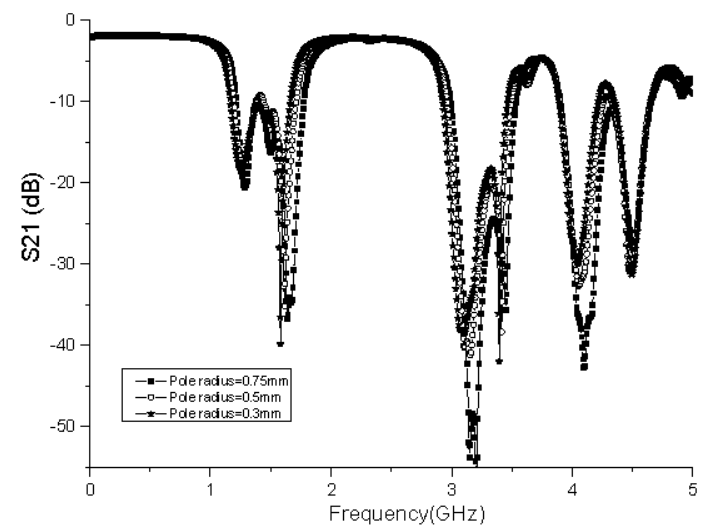

Figure 7 Comparison of $\mathrm{S} 21$ with different Pole radius of EBG

The parameters of the proposed HIS EBG are selected as follows: periodic length $P a=15 \mathrm{~mm}, P w=13.6 \mathrm{~mm}, p=1.5$, $S g=0.4 \mathrm{~mm}, \quad S a=2.0 \mathrm{~mm}, \quad g=1.4 \mathrm{~mm}$, width of strip $w=0.8 \mathrm{~mm}$. As shown in Figure 7, the simulated results show that the centre frequency increases somewhat with increase of radius of via pole size.

\section{Conclusions}

The novel compact and multiband EBG structures are designed and fabricated. The effects of parameters on stopband characteristics for the proposed EBG structure are studied in detail. In comparison with the conventional square patch high impedance surface structure, the proposed EBG structure can reduce the centre stopband frequencies by $40 \%$ for the same periodic length. Secondly, the proposed EBG structure can provide multiple bandstops, which can be applied to multiband antennas. By adjusting the ratio of the log periodic, the ratio of the centre frequency for multi-band frequencies can be also tuned.

\section{Acknowled gement}

This work is supported by Science Foundation Ireland.

\section{References}

[1] D.Sievenpiper, L.J.Zhang, R.F.Broas, N.G.Alexopolous, E.Yablonovitch, High-Impedance Electromagnetic Surface with a Forbidden Frequency Band, IEEE Transactions on Microwave Theory and Techniques, vol.47, No.11, Nov. 1999, pp. 2059-2074.

[2] S.P.Rea, D.Linton, E.Orr and J.McConnell, Broadband High-impedance Surface Design for Aircraft HIRF Protection, IEE Proc.-Microwave Antennas Propagation, Vol.153, No.4, Aug. 2006, pp.307-313.

[3] L.Li, B.Li, H.X.Liu,C.H.Liang, Locally Resonant Cavity Cell Model for Electromagnetic Band Gap Structures, IEEE Transactions on Antennas and Propagation, Vol.54, No.1, Jan. 2006, pp.90-100.

[4] C.R.Simovski, A.A.Sochava, High-Impedance Surface Based on Self-Resonant Grids. Analytical Modelling and Numerical Simulations, Progress In Electromagnetics Research, PIER No. 43, 2003 , pp.239-256.

[5] S.Tse, B.S.Izquierdo, J.C.Batchelor, R.J.Langley, Reduced Sized Cells for Electromagnetic Bandgap Structures, Electronics Letters, Vol.39, No.24, $27^{\text {th }}$ Nov. 2003, pp.1699-1701.

[6] Folayan, R.J.Langley, Wideband Reduced Size Electromagnetic Bandgap Structure, Electronics Letters, Vol.41, No.20, $29^{\text {th }}$ Sept. 2005, pp.1099-1100.

[7] S.Clavijo, R.E.Diaz, and W.E.McKinzie, Design Methodology for Sievenpiper High-Impedance Surfaces: An Artificial Magnetic Conductor for Positive Gain Electrically Small Antennas, IEEE Transactions on Antennas and Propagation, Vol.51, No.10, Oct. 2003, pp. 2678-2690 